University of Nebraska - Lincoln

DigitalCommons@University of Nebraska - Lincoln

USDA National Wildlife Research Center - Staff Publications
U.S. Department of Agriculture: Animal and Plant Health Inspection Service

2010

\title{
Acetaminophen as an Oral Toxicant for Nile Monitor Lizards (Varanus niloticus) and Burmese Pythons (Python molurus bivittatus)
}

\author{
Richard E. Mauldin \\ USDA-APHIS-Wildlife Services, Richard.E.Mauldin@usda.gov \\ Peter J. Savarie \\ USDA-APHIS-Wildlife Services
}

Follow this and additional works at: https://digitalcommons.unl.edu/icwdm_usdanwrc

Part of the Environmental Sciences Commons

Mauldin, Richard E. and Savarie, Peter J., "Acetaminophen as an Oral Toxicant for Nile Monitor Lizards (Varanus niloticus) and Burmese Pythons (Python molurus bivittatus)" (2010). USDA National Wildlife Research Center - Staff Publications. 943.

https://digitalcommons.unl.edu/icwdm_usdanwrc/943

This Article is brought to you for free and open access by the U.S. Department of Agriculture: Animal and Plant Health Inspection Service at DigitalCommons@University of Nebraska - Lincoln. It has been accepted for inclusion in USDA National Wildlife Research Center - Staff Publications by an authorized administrator of DigitalCommons@University of Nebraska - Lincoln. 


\title{
Acetaminophen as an oral toxicant for Nile monitor lizards (Varanus niloticus) and Burmese pythons (Python molurus bivittatus)
}

\author{
Richard E. Mauldin ${ }^{\mathrm{A}, \mathrm{B}}$ and Peter J. Savarie ${ }^{\mathrm{A}}$ \\ A United States Department of Agriculture, Animal and Plant Health Inspection Service, Wildlife Services, \\ National Wildlife Research Center, 4101 LaPorte Avenue, Fort Collins, Colorado 80521, USA. \\ ${ }^{B}$ Corresponding author. Email: Richard.E.Mauldin@usda.gov
}

\begin{abstract}
Context. Invasive species are a growing global problem. Biological invasions can result in numerous harmful impacts on local ecologies, and non-native herpetofauna are frequently ignored. Nile monitor lizards (Varanus niloticus) and Burmese pythons (Python molurus bivittatus, recently reassessed as Python bivittatus bivittatus), have become established in southern Florida. Both are large, semi-aquatic predators that pose serious threats to a variety of threatened and endangered species, as well as to the unique ecology of the area.

Aims. Acetaminophen (CAS\#103-90-2), a lethal oral toxicant for the invasive brown treesnake (Boiga irregularis) on Guam, was investigated as a possible toxicant in juvenile Burmese pythons and Nile monitors.

Methods. Dead neonatal mouse (DNM) baits containing 0, 10, 20, or $40 \mathrm{mg}$ acetaminophen were force-fed to Nile monitors, whereas DNM containing doses of $0,20,40$, or $80 \mathrm{mg}$ were freely consumed by Burmese pythons. Subjects were frequently observed post-treatment for general condition and position, with special attention paid to activity (if any), behaviour, respiration, bleeding, emesis, ataxia, and mortality.

Key results. In Nile monitors, acetaminophen doses of 10, 20, or $40 \mathrm{mg}$ resulted in 0, 50 and 100\% mortality, respectively. In Burmese pythons, doses of 20,40 , or $80 \mathrm{mg}$ resulted in $14.3,85.7$ and $100 \%$ mortality, respectively. No mortality was observed in control individuals of either species. A negative correlation between dosage $\left(\mathrm{mg} \mathrm{kg}^{-1}\right)$ and time-to-death was observed in both species. Dosages ranging from 522 to $2438 \mathrm{mg} \mathrm{kg}^{-1}$ and 263 to $703 \mathrm{mg} \mathrm{kg}^{-1}$ were uniformly lethal to monitors and pythons, respectively. Neither species exhibited signs of pain or discomfort following acetaminophen treatment.

Conclusions. Acetaminophen is an effective toxicant in juvenile Nile monitors and Burmese pythons. Further investigation into acetaminophen toxicity in adults of these species is merited.

Implications. Although further investigation into adult lethal dosages and strategies to optimise bait deployment while minimising secondary hazards is required, acetaminophen may have a role to play in the control of these invasive species in Florida.
\end{abstract}

Additional keywords: acetaminophen, Burmese python, Florida, invasive species, Nile monitor, Python molurus bivittatus, Varanus niloticus.

\section{Introduction}

Invasive species are one of the leading causes of worldwide biodiversity loss (Pimentel 2002), and the recognition that such biological invasions are of global concern has occurred only within the past 60 years (Elton 1958). The sheer number of harmful impacts that invasive species can inflict is both extensive and alarming (Krause 2009). The problem is compounded when the invasive species is a reptile or amphibian, because herpetofauna are frequently disregarded as unimportant or ignored altogether (Krause 2009).

The state of Florida unwillingly plays host to the greatest number of established non-indigenous amphibian and reptile species in the United States (Butterfield et al. 1997), due in part to importation for the pet trade, subtropical climate, and reduced populations of native species resulting in diminished competition (Enge et al. 2004). Among the most recent and visible additions to the list of successful invasive species in Florida are the Nile monitor lizard (Varanus niloticus) and the Burmese python (Python molurus bivittatus, recently reassessed as Python bivittatus bivittatus, Jacobs et al. 2009), both large carnivorous reptiles. The initial presence of both species in southern Florida is probably the result of intentional releases by reptile dealers and pet owners or by accidental escapes from captivity. In their native habitats, both species are primarily semi-aquatic although they are found in a wide variety of environments, a characteristic that may also play a part in their successful colonisation and range expansion in southern Florida.

The Nile monitor is a large African lizard that can reach lengths up to $2 \mathrm{~m}$. Agile, aggressive, intelligent, and readily commensal, 
the lizard is a generalist predator that can swim, climb, run, and dig, facilitating the consumption of a wide array of marine, fresh water, terrestrial and arboreal prey, and is also known to hunt cooperatively (Campbell 2005). Initially established and successfully breeding in Cape Coral, Florida, c. 1990 (Enge et al. 2004), Nile monitors are expanding their range and are now found in seven southern Florida counties (Florida Fish and Wildlife Conservation Commission 2008a). Monitors pose a threat to the eggs and young of turtle species that are either endangered or of special concern such as sea turtles, diamondbacked terrapins (Malaclemys terrapin) and gopher tortoises (Gopherus polyphemus). They may also threaten populations of the ground-nesting Florida burrowing owl (Athene cunicularia floridana), as well as the young of the American alligator (Alligator mississippiensis) and endangered American crocodile (Crocodylus acutus; Campbell 2003; Enge et al. 2004).

The Burmese python is among the largest of the python species, reaching lengths of $7 \mathrm{~m}$ and weighing as much as $91 \mathrm{~kg}$. The species has an extensive native geographic distribution, ranging from India and Nepal (small, disjunct populations), through most of south-eastern Asia into portions of Indonesia (Barker and Barker 2008). Burmese pythons are most often found in rainforests and marshy areas, and, being accomplished swimmers, are strongly associated with water (Barker and Barker 2008). When smaller, Burmese pythons are also skilled climbers, but tend to be more terrestrial because increasing size makes climbing problematic (Murphy and Henderson 1997). They prey primarily on appropriately sized mammals and birds, which are killed by constriction. Burmese pythons were probably introduced into the wild in southern Florida during the 1980s when they were first observed in the saline glades and mangroves of southern Everglades National Park (ENP; Meshaka et al. 2000). Pythons have been found in at least three southern Florida counties, and their range is expanding (Florida Fish and Wildlife Conservation Commission 2008b). Pythons are known to consume the endangered Key Largo woodrat (Neotoma floridana smalli, Greene et al. 2007) and the possible expansion of the python's range southward into the Florida Keys threatens a large number of endangered species, including the rice rat (Oryzomys palustris natator), the Lower Keys marsh rabbit (Sylvilagus palustris hefneri) and Florida Key deer (Odocoileus virginianus clavium). Snow et al. (2007) examined the stomach contents of pythons taken in or near ENP and reported finding cottontail rabbits (Sylvilagus spp.), bobcats (Lynx rufus), raccoons (Procyon lotor), oppossums (Didelphis spp.), alligators, and a variety of wading birds and rodents.

Currently, there are no established, systematic operational control methods for either of these reptiles. Nile monitors have been successfully live-trapped (Campbell 2005), whereas attempts to live-trap Burmese pythons have not been effective (Campbell 2005; USFWS 2007). Various federal and Florida state agencies have begun cooperating to develop control strategies, and the use of toxicants may have a role in the control of both species. Acetaminophen (CAS\# 103-90-2) is an effective oral toxicant for the invasive brown treesnake (Boiga irregularis) and is used operationally in an integrated program by the US Department of Agriculture, Wildlife Services, to control the snakes on the island of Guam
(Engeman and Vice 2001; Vice and Pitzler 2002; D. S. Vice, pers. comm., 2009). Savarie et al. (2001a) evaluated acetaminophen in laboratory efficacy tests by free-feeding captive brown treesnakes (47-300 g) with a single dead, frozen/thawed neonatal mouse (DNM) containing tableted acetaminophen doses of $0,10,20,40$, or $80 \mathrm{mg} \mathrm{snake}^{-1}$. The $40-\mathrm{mg}(n=10)$ and $80-\mathrm{mg}(n=29)$ doses resulted in $100 \%$ mortality; $67 \%$ mortality was observed with the 20 -mg dose $(n=9)$. No mortality was observed at the $10-\mathrm{mg}$ dose $(n=8)$. Because snakes in excess of $300 \mathrm{~g}$ could be encountered in the field, the 80 -mg acetaminophen dose was chosen for use in subsequent field trials.

Savarie et al. (2001a, 2001b) suspended a series of bait stations made of PVC pipe (10.2-cm diameter $\times 20.5-\mathrm{cm}$ length) in vegetation around the perimeter of each of six unbounded plots (three treated, three control) of $\sim 6$ ha each in adjacent forested areas on Guam. A DNM containing $80 \mathrm{mg}$ of acetaminophen was placed in each of the bait stations on the treated plots, and an unadulterated DNM was similarly placed in each station on the control plots. Acetaminophen treatment resulted in near-total elimination of brown treesnakes from treated plots compared with control plots (Savarie et al. $2001 b$ ). Because of its demonstrated effectiveness and minimal hazard to non-target species such as land crabs (Savarie et al. 2001c) and the endangered Mariana crow (Corvus kubaryi, Avery et al. 2004), acetaminophen was registered for use in controlling brown treesnakes in Guam by the US Environmental Protection Agency. As with live traps (Rodda et al. 2007; Tyrrell et al. 2009), DNM baits may not target smaller snakes and techniques for delivery of baits to this subgroup of snakes need further investigation.

The successful invasion of the brown treesnake on Guam and its devastating impact on the island's avifauna provides a cautionary tale of the repercussions of delay in dealing with invasive predators (Savidge 1987). Effective tools and strategies are required to limit if not reduce or eliminate the nascent populations of Nile monitors and Burmese pythons in southern Florida. The study described in the present report represents an initial investigation into the effectiveness of acetaminophen as a control agent for these invasive reptiles.

\section{Materials and methods}

All research was conducted at the National Wildlife Research Center (NWRC) in Fort Collins, Colorado, USA, and performed according to a protocol (QA-1496) approved by the Institutional Animal Care and Use Committee. Imported juvenile Burmese pythons farm-raised in Vietnam and Nile monitors wild-caught in Africa were obtained from Ballroom Pythons South (Haines City, FL, USA). All arrived at the NWRC in apparent good condition. On arrival, monitors were individually numbered, weighed and housed singly in a 57 -L aquarium $(31.1 \times 61 \times 32.4 \mathrm{~cm}$, with a screen top $)$. Each aquarium contained a water bowl $(17.8 \mathrm{~cm}$ diameter $)$ and a PVC hide tube made by cutting a $15.9-\mathrm{cm}-$ long section of $15.2-\mathrm{cm}-$ diameter pipe in half lengthwise. A thin cardboard sheet was used as a substrate. Additional heat was provided by a $15-\mathrm{W}$ heat lamp placed above the aquarium at one end.

Each aquarium was then placed into a four-shelf rack that housed four aquariums per shelf. Cardboard partitions were 
inserted between aquariums to visually isolate each monitor. Juvenile Nile monitors cannot be sexed by probe or visual inspection (T. Campbell, DVM, Colorado State University, pers. comm.), so sex was not determined.

Each python was individually numbered, weighed, sexed by probing the hemipenes, and housed singly in a clear, polycarbonate-lidded box measuring $45.5 \times 66.0 \times 17.0 \mathrm{~cm}$ (Cambro Mfg. Co, Huntington Beach, CA, USA). Each box contained a water bowl $(17.8 \mathrm{~cm}$ diameter), PVC hide tube ( $5 \mathrm{~cm}$ diameter $\times 22 \mathrm{~cm}$ long) and sheet-paper bedding. Each box was loaded onto a four-shelf rack that housed three boxes per shelf. Additional heat was supplied by $30-\mathrm{W}$ mylar substrate heaters (Ultratherm, Scotland).

Both species were housed on opposite ends of an environmentally controlled room measuring $3.75 \times 14.1 \mathrm{~m}$. The room was maintained at $\sim 30^{\circ} \mathrm{C}$ and $55 \%$ relative humidity with a $12 \mathrm{~h}$ light $/ 12 \mathrm{~h}$ dark photocycle (lights on at 0700 hours Mountain Standard Time (MST), off at 1900 hours MST). Monitors were fed a single mouse three times weekly, and, because of the wide range of lizard masses, fed either hairless or furred neonate mice ranging in mass from $2.0 \mathrm{~g}$ to $4.2 \mathrm{~g}(\sim 4.7 \%$ of average lizard mass). Pythons were fed furred DNM twice weekly, ranging in mass from $3.8 \mathrm{~g}$ to $6.5 \mathrm{~g}(\sim 3.9 \%$ of average python mass). Monitors were given a 3 -week acclimation period before toxicity trials, whereas pythons, which took longer to begin accepting food and eating regularly, were given 7 weeks to acclimate.

\section{Acetaminophen tablet preparation}

Acetaminophen tablets were prepared by adding the appropriate amount of acetaminophen to fixed percentages of matrix ingredients, which included polyvinyl pyrollidone binder $(2.8 \%)$, carboxymethylcellulose disintegrant $(0.9 \%)$, microcrystalline cellulose binder $(17 \%)$ and dibasic calcium phosphate filler (3.7\%). Magnesium stearate $(0.3 \%)$ and stearic acid $(0.6 \%)$ were included as tablet press lubricants. Tablets varied in size, ranging from 3 to $7 \mathrm{~mm}$ in diameter and from 1 to $2 \mathrm{~mm}$ in width. Prior to treatment, a tablet containing the appropriate acetaminophen dose (or DNM only, for controls) was inserted deep into the esophagous of a pre-weighed DNM which was just large enough to accommodate the tablet. DNM were chosen as the toxicant carrier to mimic the ingestion of an actual treated bait. Both species were fed sizeappropriate DNM which were as small as possible to minimise possible tissue mass-related interference with acetaminophen release and absorption. Chemical analysis of five samples each of the 0-, 10-, 20-, 40- and 80-mg tablets yielded actual mean \pm s.d. acetaminophen content of $0,10.1 \pm 0.62,19.0 \pm 1.1$, $39.5 \pm 0.90$ and $77.1 \pm 2.6 \mathrm{mg}$, respectively. Dosage calculations ( $\mathrm{mg}$ acetaminophen per kg body mass) were based on the actual determined dose.

\section{Treatment}

\section{General}

Because the response of both monitors and pythons to acetaminophen was unknown, toxicity testing in both species required an initial range-finding phase, utilising a control group and a single treatment group that received a 40-mg acetaminophen dose. This dose was chosen because, as mentioned previously, it was the minimum dose found to yield $100 \%$ mortality in similarly sized brown treesnakes. One to three days before treatment, monitors and pythons were weighed and weight ranked from lowest to highest in sets of four. By using the online randomisation program (Research Randomize, http://www.randomizer.org/about.htm), each of the four monitors/pythons in a ranked set were then randomly assigned to one of four experimental groups (control, $40 \mathrm{mg}$ acetaminophen, and two groups with doses to be determined). Since the sex of each python was known, the weight-ranking procedure was performed separately for males and females in an attempt to equalise the sex ratio in each experimental group.

The results of the range-finding phase determined the two remaining acetaminophen doses used in the second phase of the trial. If $40 \mathrm{mg}$ produced $0 \%$ mortality, the next doses chosen would be $80 \mathrm{mg}$ and $160 \mathrm{mg}$. Conversely, if $40 \mathrm{mg}$ resulted in $100 \%$ mortality, the next two doses would be $20 \mathrm{mg}$ and $10 \mathrm{mg}$. If mortalities of $>0 \%$ and $<100 \%$ were observed, $20 \mathrm{mg}$ and $80 \mathrm{mg}$ doses would follow to bracket the initial 40-mg dose.

Immediately before treatment, animals were reweighed to provide accurate dosage calculations. Following treatment at between 0900 hours and 1100 hours, animals were observed every $2-3 \mathrm{~h}$ until 2300 hours, with observations resuming at 0900 hours the following day. During observation, the condition and position of the animal was recorded. Special attention was paid to activity (if any), behaviour, respiration rate, signs of bleeding, emesis, ataxia or mortality. Animals that expired during the treatment period were weighed and examined for any external abnormalities. The time at which mortality was observed was taken as the actual time-to-death (TTD). The post-treatment observation period lasted 7 days, at the end of which, all surviving animals (except for controls) were terminated by $\mathrm{CO}_{2}$ inhalation, weighed and incinerated. Linear regression analysis of dosage against TTD was performed using the PROC REG program (SAS Institute Inc., Cary, NC, USA).

\section{Monitor lizards}

Monitors were fasted 1-3 days before treatment. During the acclimation phase, monitors were observed tearing, mangling or dismembering their prey. To avoid possible acetaminophen loss, monitors were force-fed by inserting an avian oral speculum into the mouth and pushing until the mouth opened widely. The dosed, size-appropriate DNM was then inserted into the throat, the speculum was removed, the throat was gently massaged to push the DNM towards the stomach, and the monitor was returned to its cage. DNMs ranged in mass from 2.0 to $4.7 \mathrm{~g}$. To minimise disturbance, monitors hiding under the paper substrate were observed with a mirror placed under the aquarium, aided by a flashlight when observations were made in darkness. There were eight monitors for each of the four doses $(0,10,20$ and $40 \mathrm{mg})$ tested.

\section{Burmese pythons}

Pythons were fasted 3-7 days before treatment. On treatment day, each python was weighed and returned in its respective box to allow recovery and relaxation from handling. Treated or control DNM were then offered on tongs, and were usually taken and consumed immediately. If the DNM was refused, it was placed near the python and observed every 
Table 1. Acetaminophen dose-related mortality and approximate time-to-death data (mean \pm s.d.) in Nile monitors Values in parentheses are ranges

\begin{tabular}{lcccr}
\hline $\begin{array}{l}\text { Acetaminophen } \\
\text { dose }(\mathrm{mg})\end{array}$ & Body mass $(\mathrm{g})$ & $\begin{array}{c}\text { Dosage (mg acetaminophen } \\
\text { per kg body mass) }\end{array}$ & Mortality & $\begin{array}{c}\text { Approximate } \\
\text { time-to-death (h) }\end{array}$ \\
\hline 0 & $65.6 \pm 32.0(21.0-106)$ & 0 & $0 / 8$ & No mortality \\
10.1 & $73.0 \pm 42.3(23.5-150)$ & $199 \pm 138(67.5-430)$ & $0 / 8$ & No mortality \\
19 & $66.8 \pm 34.4(19.7-122)$ & $406 \pm 300(155-965)$ & $4 / 8$ & $55.1 \pm 33.9(31.3-95.0)$ \\
39.5 & $62.1 \pm 32.7(16.2-105)$ & $934 \pm 723(377-2438)$ & $8 / 8$ & $27.3 \pm 8.6(23.8-48.5)$ \\
\hline
\end{tabular}

$2-3 \mathrm{~h}$ to determine the actual consumption time. Uneaten DNM were left in the box overnight, and, if not consumed by the following morning, were replaced with a fresh control/treated DNM. If a DNM had not been consumed within 3 days, the python was force-fed a fresh control/treated DNM. DNMs ranged in mass from 3.8 to $6.5 \mathrm{~g}$. The acetaminophen doses tested and associated group sizes were $0(n=5), 20(n=7), 40(n=7)$ and $80 \mathrm{mg}(n=7)$.

\section{Results}

Nile monitors

Results of acetaminophen dose-related mortality and approximate TTD data in Nile monitors are summarised in Table 1 . The $100 \%$ mortality observed with the $40-\mathrm{mg}$ dose resulted in subsequent trials utilising $20 \mathrm{mg}$ and $10 \mathrm{mg}$. The 20-mg dose yielded 50\% mortality; no mortality was observed with $10 \mathrm{mg}$.

Acetaminophen dosages were highly variable within groups, with much overlap among groups. In many instances, a dosage resulted in mortality at one dose whereas a similar dosage at a different dose did not. Dosages of 204.3 and $228.6 \mathrm{mg} \mathrm{kg}^{-1}$, as well as 788.4 and $964.5 \mathrm{mg} \mathrm{kg}^{-1}$ yielded mortality in the 20-mg dose treatment, whereas dosages ranging from 199.6 to $429.8 \mathrm{mg} \mathrm{kg}^{-1}$ in the 10 -mg dose treatment were not lethal. All acetaminophen dosages from 522 to $2438 \mathrm{mg} \mathrm{kg}^{-1}$ $\left(\bar{X}=1056 \pm 651.4 \mathrm{mg} \mathrm{kg}^{-1}\right)$ were lethal to juvenile monitor lizards.

Treated monitors behaved similarly to controls, with no overt signs of pain or discomfort. No bleeding or ataxia were observed. Most monitors crawled under the cardboard substrate and slept, and many died in the resting positions assumed following treatment. Basking under the heat lamp was also frequently observed. Respiration rates in all monitors were typically slow, and, along with activity, appeared to increase in response to the proximity of the observer. Extreme lethargy and unresponsiveness were observed just before death in several monitors from the 20-mg and 40-mg treatment groups, but not in controls or monitors from the 10-mg dose. Roughly half of the lizards in both the 20-mg and 40-mg groups vomited the partially digested treated DNM just before death. Linear regression analysis of dosage against TTD yielded the equation $y=-0.0176 x+50.7$, with a $P$-value of 0.114 and an associated $r^{2}$ of 0.231 . The regression is depicted in Fig. 1.

\section{Burmese pythons}

Results of acetaminophen toxicity testing in Burmese pythons are summarised in Table 2. The $85.7 \%$ mortality observed with the 40-mg dose resulted in subsequent trials utilising $80 \mathrm{mg}$ and $20 \mathrm{mg}$. The $80 \mathrm{mg}$ dose yielded $100 \%$ mortality, whereas the 20 -mg dose resulted in $14.3 \%$ mortality. Dosages from 263 to $703 \mathrm{mg} \mathrm{kg}^{-1}$ ( $\overline{\mathrm{X}}=458 \pm 140 \mathrm{mg} \mathrm{kg}^{-1}$ ) were lethal, regardless of the dose administered. Regression analysis of dosage by TTD produced the equation $y=-0.0423 x+50.0$, with an associated $r^{2}$ of 0.495 and a significant $P$-value of 0.005 (see Fig. 2).

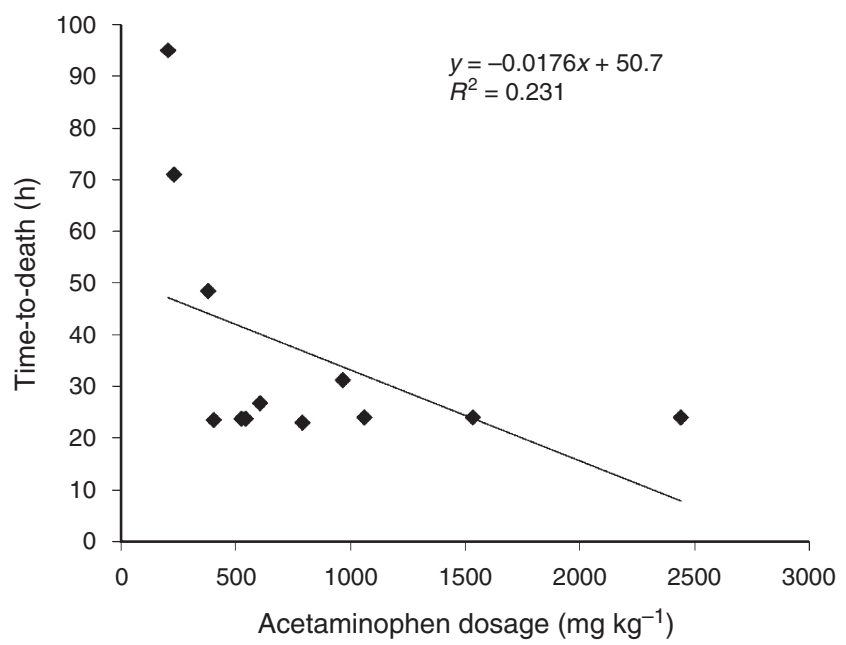

Fig. 1. Regression of acetaminophen dosage by time-to-death (h) in Nile monitors.

Table 2. Acetaminophen dose-related mortality and approximate time-to-death data (mean \pm s.d.) in Burmese pythons Values in parentheses are ranges

\begin{tabular}{lcccc}
\hline $\begin{array}{l}\text { Acetaminophen } \\
\text { dose }(\mathrm{mg})\end{array}$ & Body mass $(\mathrm{kg})$ & $\begin{array}{c}\text { Dosage }(\mathrm{mg} \text { acetaminophen } \\
\text { per kg body mass) }\end{array}$ & Mortality & $\begin{array}{c}\text { Approximate } \\
\text { time-to-death (h) }\end{array}$ \\
\hline 0 & $138 \pm 40.2(102-199)$ & 0 & $0 / 5$ & No mortality \\
19 & $118 \pm 24.6(78.7-149)$ & $167 \pm 37.3(128-241)$ & $1 / 7$ & 47.8 \\
39.5 & $133 \pm 27.8(89-165)$ & $310 \pm 74.6(239-445)$ & $6 / 7$ & $35.7 \pm 9.7(22.8-47.2)$ \\
77.1 & $146 \pm 29.2(127-191)$ & $546 \pm 105(403-703)$ & $7 / 7$ & $26.8 \pm 6.0(21.0-30.5)$ \\
\hline
\end{tabular}




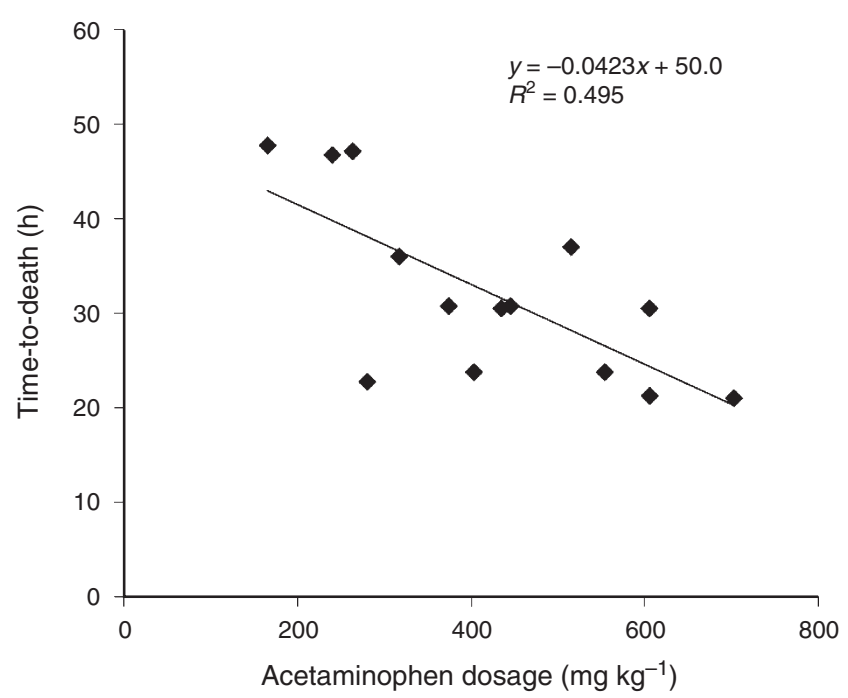

Fig. 2. Regression of acetaminophen dosage by time-to-death (h) in Burmese pythons.

As with the monitors, treated pythons behaved similarly to controls, and no overt symptoms of post-treatment pain or discomfort were noted. No bleeding or ataxia was observed, and both respiration and activity was stimulated by observer presence. Pythons were most frequently observed coiled in various parts of the box, or in the hide tube.

Treated pythons were frequently observed to be sluggish and unresponsive before death, and many pythons that had been coiled and resting for the entire post-treatment period were often seen crawling around the box periphery immediately before expiration.

Several pythons in the 40-mg group appeared bloated before death, and this condition was even more pronounced in the $80-\mathrm{mg}$ dose group. Necropsy examination of a few of these individuals revealed that the trachea and lungs were partially filled with clear, colorless, semi-viscous fluid. Anterior pulmonary hemorrhaging was also noted in one python.

\section{Discussion}

The acetaminophen doses of $40 \mathrm{mg}$ and $80 \mathrm{mg}$, which resulted in total or near-total lethality for both monitors and pythons, were virtually identical to the $40-\mathrm{mg}$ and $80-\mathrm{mg}$ doses shown to be completely effective in brown treesnakes of similar weights. Treated monitors/pythons displayed no apparent signs of suffering or distress; similarly, no signs of discomfort were exhibited by treated brown treesnakes (P. J. Savarie, unpubl. data). Interestingly, the emesis noted in monitor lizards was also observed in several brown treesnakes treated with 40 and $80 \mathrm{mg}$ of acetaminophen (Savarie et al. 2001a), but only one python in the 80-mg dose group vomited the treated DNM. In both monitors and pythons, mortality fell off sharply with decreasing dose, decreasing from $100 \%$ to $0 \%$ with doses of $40 \mathrm{mg}$ and $10 \mathrm{mg}$, respectively, in monitors, and from $85.7 \%$ to $14.3 \%$ with doses of $40 \mathrm{mg}$ and $20 \mathrm{mg}$, respectively, in pythons.

Linear equations produced by regression analysis of dosage by TTD were remarkably similar. A negative correlation of dosage with TTD was significant in pythons but not significant in monitors. This may have been due to the misleading nature of the TTD values when mortality was observed during the first observation of the morning. Because that observation time was given as the TTD, it obscured the possibility of overnight mortality occurring as much as $10 \mathrm{~h}$ earlier. This situation was prevalent in TTD estimates at the 40-mg dose level in monitors. Average mortality was given as $27.3 \mathrm{~h}$, although six of eight lizards probably died earlier than reported. The significant correlation found in pythons was aided by the decreased variability in body mass range, which led to much less variation in the dosage range within a given acetaminophen dose. The decreased mass range was the result of similar origin and ages of the juvenile pythons, whereas with wild-caught juvenile Nile monitors, the variable weights were probably a result of differing ages.

The mechanism of acetaminophen toxicity in reptiles is not known, although it may be due to liver and kidney toxicity (National Toxicology Program 1993), possibly via glutathione depletion, which can lead to hepatic necrosis (Gosselin et al. 1984). Another possibility is the occurrence of methemoglobinemia, which has been observed in cats that have ingested acetaminophen (Finco et al. 1975). Methemoglobinemia is a condition in which a larger than normal percentage of circulating hemoglobin occurs as methemoglobin, a form of hemoglobin that does not carry oxygen. Acetaminophen-treated brown treesnakes also displayed severe methemoglobinemia (T. Mathies, unpubl. data).

\section{Extrapolating lethal acetaminophen doses}

Further research is required to determine acetaminophen dosages that would be consistently lethal to pythons and monitors at adult masses. Whether effective and practical doses for use in adult monitors or pythons can be predicted by scaling up the doses employed herein, by using an isometric/allometric weight relationship also remains to be explored. In pythons collected in or around the ENP between January 2003 and March 2006, Snow et al. (2007) found that the mean mass of males $(n=27)$ was $8.30 \pm 1.23 \mathrm{~kg}$, and the mean mass of females $(n=29)$ was $12.1 \pm 2.10 \mathrm{~kg}$. The overall weighted mean body mass of these snakes was $10.3 \mathrm{~kg}$. Hypothetically, scaling isometrically from the data in the current report, multiplying the average adult python body mass of $10.3 \mathrm{~kg}$ by the mean lethal dosage in juvenile pythons of $458 \mathrm{mg} \mathrm{kg}^{-1}$ gives the expression $458 \mathrm{mg} \mathrm{kg}^{-1} \times 10.3 \mathrm{~kg}=4717 \mathrm{mg}(4.72 \mathrm{~g})$ acetaminophen, a dose that could be lethal to the average adult python found at ENP. If, however, dose effectiveness follows an allometric scaling of metabolism (i.e. mass-specific metabolic rates decrease with increasing body mass), less acetaminophen could be used. Secor and Diamond (1997) calculated a body mass scaling exponent of 0.9 when measuring peak $\mathrm{VO}_{2}$ (aerobic capacity) during digestion for Burmese pythons fed meals equal to $25 \%$ of the snake's body mass. If applied to the mean ENP python mass of $10.3 \mathrm{~kg}$ cited previously, the expression becomes $458 \mathrm{mg} \mathrm{kg}^{-1} \times 10.3^{0.9} \mathrm{~kg}=3737 \mathrm{mg}(3.74 \mathrm{~g})$ acetaminophen to achieve lethality in an average adult python. Using the exponent derived from measuring $\mathrm{VO}_{2}$ during digestion seems particularly applicable, because the toxicant would likely be delivered in a consumable prey item, requiring digestion to mobilise the toxicant. 
Table 3. Acetaminophen acute oral toxicity to a variety of mammal and bird species

\begin{tabular}{|c|c|c|}
\hline Species & Dosage $\left(\mathrm{mg} \mathrm{kg}^{-1}\right)$ and result & Reference \\
\hline \multirow[t]{2}{*}{ House mouse (Mus musculus) } & 338 - LD50 & Starmer et al. (1971) \\
\hline & $1200-\mathrm{LD} 50$ & Bousquet et al. (1996) \\
\hline \multirow[t]{2}{*}{ Norway rat (Rattus norvegicus) } & $2393-\mathrm{LD} 50$ & Ekwall et al. (1989) \\
\hline & $3700-$ LD50 & Boxill et al. (1958) \\
\hline Guinea-pig (Cavia cobaya) & $2620-$ LD50 & Boxill et al. (1958) \\
\hline Brushtail possum (Trichosurus vulpecula) & 2000 - no mortality & Eason et al. (1999) \\
\hline Northern bobwhite quail (Colinus virginianus) & 2250 - no mortality & Gallager and Beavers (2001) \\
\hline Fish crow (Corvus ossifragus) & $\begin{array}{l}80 \mathrm{mg} \mathrm{bird}{ }^{-1}-0 / 5 \text { died } \\
160 \mathrm{mg} \mathrm{bird}^{-1}-1 / 5 \text { died }\end{array}$ & Avery et al. (2004) \\
\hline
\end{tabular}

Body mass data collected from $\sim 200$ adult Nile monitors sampled around Cape Coral, Florida, indicated that most weighed between 1 and $3 \mathrm{~kg}$, with a mean of $\sim 2 \mathrm{~kg}$ (T. Campbell, pers. comm.). A hypothetical isometrically scaled adult-monitor lethal-dose prediction using the mean lethal acetaminophen dosage of $1056 \mathrm{mg} \mathrm{kg}^{-1}$ reported previously and the average adult-monitor mass of $2 \mathrm{~kg}$ yields a lethal adult-monitor dose of $2112 \mathrm{mg}(2.11 \mathrm{~g})$ acetaminophen. Estimation of an allometrically scaled adult-lizard dose utilises the mass scaling standard metabolic rate exponent of 0.84 obtained by Secor and Phillips (1997). These authors studied metabolic responses of the white-throated monitor lizard (Varanus albigularis), a lizard that, like the Nile monitor, occurs in central and southern Africa. When applied to the mean monitor-lizard mass of $2 \mathrm{~kg}$ cited previously, a corrected average adult lizard mass of $1.79 \mathrm{~kg}$ results. Multiplying $1.79 \mathrm{~kg}$ by $1056 \mathrm{mg} \mathrm{kg}^{-1}$ yields an estimated adult lethal dose of $1890 \mathrm{mg}$ $(1.89 \mathrm{~g})$ acetaminophen.

As stated previously, the mean lethal dosage used in the preceding calculations represents the average of a range of lethal dosages found in the present study and may overestimate the actual lethal dose required. These values for acetaminophen lethality in adult pythons and lizards are highly speculative and should be regarded as a guide for further experimentation and not as an operational prescription.

\section{Non-target hazards}

Although acetaminophene toxicity has now been demonstrated in three species of reptiles, i.e. brown treesnakes, Nile monitors, and Burmese pythons, it is usually less toxic to endotherms. Table 3 summarises the acute oral toxicity of acetaminophen in a variety of mammal and bird species.

Accurate risk assessment calculations of primary and secondary hazards to non-target species require data on the toxicant dose or expected toxicant concentrations in a particular situation (e.g. used in a bait). Johnston et al. (2002) found that the use of acetaminophen-treated mouse baits to control the brown treesnake on Guam posed minimal nontarget risks when weighed against the known damage inflicted by the invasive snake. In that case, extensive prior laboratory and field research had led to the point that these authors knew how the toxicant was going to be deployed and the acetaminophen concentrations to be expected (Shivik and Clark 1997; Savarie et al. 2001a, 2001b, 2001c). The initial and limited results in the present study are inadequate for this purpose, and substantial research remains to be conducted using adult pythons and monitors to clarify these issues and provide relevant dose data for accurately assessing non-target risk concerns. However, an initial discussion of possible acetaminophen deployment methods and presentation issues is appropriate as a general introduction to some of the questions that remain to be resolved for baiting Nile monitor lizards and Burmese pythons.

It is useful to remember that doses of any toxicant must be delivered in a palatable, attractive bait. Delivery of acetaminophen in carcasses of medium-to-large $(0.5-2 \mathrm{~kg})$ frozen, thawed mammals such as rabbits or piglets would serve to limit availability to non-target species simply by preysize constraints. This would also select for size cohorts within the target species large enough to take larger baits, especially if the target species consume the treated-bait whole. Further, acetaminophen would likely be inserted as a bolus deep within the body cavity of the treated carcass, further isolating the toxicant from potential scavengers.

Placement of treated baits, such as suspension from a branch or held off the ground on a pole or attached to a tree trunk could serve as a further non-target barrier. Such placement might have the additional advantage of requiring climbing ability (which both target species possess) to access the bait, which would limit availability to large non-targets unable to climb significant heights, such as crocodilians. Treated bait carcasses could also be placed in suspended/elevated PVC tubing of appropriate length and diameter, which would limit access by non-targets with wide heads or short limbs, and might also serve as an attractive shelter to pythons and monitors that could enter easily by virtue of narrow heads and necks (D. Beard, pers. comm. 2009). In an operational setting, manipulating combinations of treated-bait size and presentation could serve to limit non-target hazard dramatically. These approaches are by no means allencompassing; however, they serve as a starting point for further investigation.

Obviously, extensive research into target size-acetaminophen dose relationships, minimising secondary hazards, and eventual methods of deployment will be required before acetaminophen can be considered for use in the control of Burmese pythons or Nile monitors in southern Florida.

\section{Conclusions}

Acetaminophen is an effective toxicant in juvenile Nile monitors and Burmese pythons when administered in a DNM. An 80-mg dose resulted in $100 \%$ mortality in monitors ranging in mass from 
16.2 to $105 \mathrm{~g}$, whereas $40-\mathrm{mg}$ and $80-\mathrm{mg}$ doses yielded $85.7 \%$ and $100 \%$ mortality, respectively, in pythons ranging in mass from 89 to $191 \mathrm{~g}$. Dosages ranging from 522 to $2438 \mathrm{mg} \mathrm{kg}^{-1}$ and 263 to $703 \mathrm{mg} \mathrm{kg}^{-1}$ were uniformly lethal to monitors and pythons, respectively. An inverse relationship between dosage and TTD was observed, and no signs of pain or discomfort during intoxication were noted. Although extensive further investigation is required to ascertain appropriate lethal dosages in wild adult pythons and monitors as well as minimisation of secondary hazards and bait-deployment methods, acetaminophen may have a role in the control of these invasive species in Florida.

\section{Disclaimer}

Use of a trade name does not constitute endorsement by the USA government.

\section{Acknowledgements}

We thank Doug Beard of Flora and Fauna of South Florida and Mike Cole of Ballroom Pythons South for their efforts in obtaining late-season juvenile pythons and monitors. We also deeply appreciate the efforts of the Animal Care Staff at the National Wildlife Research Center in accommodating and caring for these animals. We also thank Christi Yoder for performing the statistical analyses, Jerry Hurley for the preparation of acetaminophen tablets, and Carol Furcolow and Doreen Griffin of the Analytical Chemistry Project at NWRC for the acetaminophen tablet analysis.

\section{References}

Avery, M. A., Tillman, E. A., and Savarie, P. J. (2004). Responses of captive fish crows (Corvus ossifragus) to acetaminophen baits and bait stations for brown tree snake (Boiga irregularis) control on Guam. Bird Behaviour 16, 1-6.

Barker, D. G., and Barker, T. M. (2008). The distribution of the Burmese python, Python molurus bivittatus. Bulletin of the Chicago Herpetological Society 43, 33-38.

Bousquet, E., Marrazzo, A., Puglisi, G., Spadaro, A., and Tirendi, S. (1996). Synthesis, physical properties, toxicology studies, and bioavailability of L-pyroglutamic and L-glutamic acid sters of paracetamol as potentially useful prodrugs. Journal of Pharmacy and Pharmacology 48, 479-485.

Boxill, G. C., Nash, C. B., and Wheeler, A. G. (1958). Comparative pharmacological and toxicological evaluation of $\mathrm{N}$-acetyl- $p$ aminophenol, salicyamide, and acetylsalicylic acid. Journal of the American Pharmaceutical Association (Scientific Ed.) 47, 479-487.

Butterfield, B. P., Meshaka, W. E., and Guyer, C. (1997). Nonindigenous amphibians and reptiles. In 'Strangers in Paradise: Impact and Management of Nonindigenous Species in Florida'. (Eds D. Simberloff, D.C. Schmitz and T.C. Brown.) pp. 123-138. (Island Press: Washington, DC.)

Campbell, T. S. (2003). Species profile: Nile monitors (Varanus niloticus) in Florida. Iguana 10, 119-120.

Campbell, T. S. (2005). Eradication of introduced carnivorous lizards from the Cape Coral area. Final Report to the Charlotte Harbor National Estuary Program, Fort Myers, FL.

Eason, C. T., Wright, G. R. G., and Gooneratne, R. (1999). Pharmacokinetics of antipyrine, warfarin, and paracetamol in the brushtail possum. Journal of Applied Toxicology 19, 157-161. doi:10.1002/(SICI)1099-1263 (199905/06)19:3<157::AID-JAT559>3.0.CO;2-K

Ekwall, B., Bondesson, I., Castell, J.V., Gomez-Lechon, M.J., Hellberg, S., Hogberg, J., Jover, R., Ponsoda, X., Romert, L., Stenberg, K., and Walum, E. (1989). Cytotoxicity evaluation for the first ten MEIC chemicals: acute lethal toxicity in man predicted by cytotoxicity in five cellular assays and by oral LD50 in rodents. ATLA 17, 83-100.
Elton, C. S. (1958). 'The Ecology of Invasions by Animals and Plants.' (Methuen: London.)

Enge, K. M., Krysko, K. L., Hankins, K. R., Campbell, T. S., and King, F. W. (2004). Status of the Nile monitor (Varanus niloticus) in southwestern Florida. Southern Naturalist 3, 571-582. doi:10.1656/1528-7092(2004) 003[0571:SOTNMV]2.0.CO;2

Engeman, R. M., and Vice, D. S. (2001). Objectives and integrated approaches for the control of brown tree snakes. Integrated Pest Management Reviews 6, 59-76. doi:10.1023/A:1020441405093

Finco, D. R., Duncan, J. R., Schall, W. D., and Prasse, K. W. (1975). Acetaminophen toxicosis in the cat. Journal of the Veterinary Medical Association 166, 469-472.

Florida Fish and Wildlife Conservation Commission (2008a). Nile monitor, Varanus niloticus. Available at http://myfwc.com/nonnatives/exotics/ SpeciesNumberResults.asp?SPPNO=291 [accessed 6 March 2008].

Florida Fish and Wildlife Conservation Commission (2008b). Burmese python, Python molurus bivittatus. Available at http://myfwc.com/ nonnatives/exotics/SpeciesNumberResults.asp?SPPNO=46 [accessed on 6 March 2008].

Gallager, S. P., and Beavers, J. B. (2001). Acetaminophen: an acute oral toxicity study with northern bobwhite. Unpublished report submitted to USDA/National Wildlife Research Center by Wildlife International Ltd, Easton, MD. Project No. 247-105.

Gosselin, R. E., Smith, R. P., and Hodge, H. C. (1984). 'Clinical Toxicology of Commercial Products.' (Williams and Wilkins: Baltimore, MD.)

Greene, D. U., Potts, J. M., Duquesnel, J. G., and Snow, R. W. (2007). Natural history notes: Python molurus bivitattus (Burmese python). Herpetological Review 38, 3-355.

Jacobs, H. J., Auliya, M., and Böhme, W. (2009). Zur Taxonomie des dunklen Tigerpythons, Python molurus bivittatus Kuhl, 1820, speziell der Population von Sulawesi. Sauria 31, 5-16.

Johnston, J. J., Savarie, P. J., Primus, T. M., Eisemann, J. D., Hurley, J. C., and Kohler, D. J. (2002). Risk assessment of an actetaminophen baiting program form chemical control of brown tree snakes on Guam: evaluation of baits, snake residues, and potential primary and secondary hazards. Environmental Science \& Technology 36, 3827-3833. doi:10.1021/es015873n

Krause, F. (2009). 'Alien Reptiles and Amphibians: A Scientific Compendium and Analysis.' (Springer: New York.)

Meshaka, W. E. Jr, Loftus, W. F., and Steiner, T. (2000). The herpetofauna of Everglades National Park. Biological Sciences 2, 84-103.

Murphy, J. C., and Henderson, R. W. (1997). 'Tales of Giant Snakes, A Historical Natural History of Anacondas and Pythons.' (Kreiger Publishing Co.: Malabar, FL.)

National Toxicology Program (1993). 'Toxicology and Carcinogenesis Studies of Acetaminophen in F344/N Rats and B6C3F Mice.' NIH Publication No. 93-2849. (US Department of Health and Human Services)

Pimentel, D. (2002). Introduction: non-native species in the world. In 'Biological Invasions: Economic and Environmental Costs of Alien Plant, Animal, and Microbe Species'. (Ed. D. Pimentel.) pp. 1-8. (CRC Press LLC: Boca Raton, FL.)

Rodda, G. H., Savidge, J. A., Tyrrell, C. L., Christy, M. T., and Ellingson, A. R. (2007). Size bias in visual searches and trapping of brown treesnakes on Guam. The Journal of Wildlife Management 71, 656-661. doi:10.2193/ 2005-742

Savarie, P. J., Shivik, J. A., Clark, L., Linder, T. J., and York, D. L. (2001a). Laboratory and field efficacy tests of acetaminophen in brown treesnakes (Boiga irregularis). In 'Brown Treesnake 2001: Research \& Management, 6-10 August 2001, Andersen Air Force Base, Guam’. p. 21. [Abstract]

Savarie, P. J., Shivik, J. A., White, G. C., Hurley, J. C., and Clark, L. (2001b). Use of acetaminophen for large-scale control of brown treesnakes. The Journal of Wildlife Management 65, 356-365. doi:10.2307/ 3802916 
Savarie, P. J., Linder, T. J., and York, D. L. (2001c). Acetaminophen feeding tests in land hermit crabs (Coenobita brevimanus) and coconut crabs (Birgus latro). In 'Brown Treesnake 2001: Research \& Management, 6-10 August 2001, Andersen Air Force Base, Guam'. p. 20. [Abstract]

Savidge, J. A. (1987). Extinction of an island forest avifauna by an introduced snake. Ecology 68, 660-668. doi:10.2307/1938471

Secor, S. M., and Diamond, J. (1997). Determinants of postfeeding metabolic response in Burmese pythons (Python molurus). Physiological Zoology 70, 202-212.

Secor, S. M., and Phillips, J. A. (1997). Specific action of a large carnivorous lizard, Varanus albigularis. Comparative Biochemistry and Physiology 117A, 515-522.

Shivik, J. A., and Clark, L. (1997). Carrion seeking in brown tree snakes: importance of olfactory and visual cues. Journal of Experimental Zoology 279, 549-553. doi:10.1002/(SICI)1097-010X(19971215)279: $6<549::$ AID-JEZ2 $>3.0 . \mathrm{CO} ; 2-\mathrm{N}$

Snow, R. W., Brien, M. L., Cherkiss, M. S., Wilkins, L., and Mazzotti, F. J. (2007). Dietary habits of the Burmese python, Python molurus bivittatus, in the Everglades National Park, Florida. Herpetological Bulletin 101, $5-7$.
Starmer, G. A., McLean, S., and Thomas, J. (1971). Analgesic potency and acute toxicity of substituted analides and benzamides. Toxicology and Applied Pharmacology 19, 20-28. doi:10.1016/0041-008X(71)90185-2

Tyrrell, C. L., Christy, M. T., Rodda, G. H., Adams, A. A. Y., Ellingson, A. R., Savidge, J. A., Dean-Bradley, K., and Bischof, R. (2009). Evaluation of trap capture in a geographically closed population of brown treesnakes on Guam. Journal of Applied Ecology 46, 128-135. doi:10.1111/j.13652664.2008.01591.x

USFWS (2007). Burmese python biology, management, and education awareness workshop, 29 March 2007. Available at http://www.fws. gov/filedownloads/ftp_verobeach [verified April 2010].

Vice, D. S., and Pitzler, M. E. (2002). Brown treesnake control: economy of scales. In 'Human Conflicts with Wildlife: Economic Considerations'. (Ed. L. Clark.) pp. 127-131. (National Wildlife Research Center: Fort Collins, CO.)

Manuscript received 26 November 2008, accepted 27 January 2010 